\title{
Kolaborasi Pembuatan Presentasi Menggunakan Aplikasi Prezi
}

\author{
Rakhmat Purnomo ${ }^{1,{ }^{*}}$, Ahmad Fathurrozi ${ }^{1}$, Rosiana Disiati Prabandari ${ }^{1}$, \\ Sugiyatno ${ }^{1}$ \\ ${ }^{1}$ Fakultas Teknik, Universitas Bhayangkara Jakarta Raya; Jl. Raya Perjuangan, Marga Mulya, \\ Bekasi Utara, Jawa Barat 17121. Telp: 021-88955882, 889955883, e-mail: \\ rakhmat.purnomo@dsn.ubharajaya.ac.id, fathur@dsn.ubharajaya.ac.id, \\ rosiana.disiati@dsn.ubharajaya.ac.id, sugiyatno@dsn.ubharajaya.ac.id
}

*Korespondensi: e-mail: rakhmat.purnomo@dsn.ubharajaya.ac.id

\begin{abstract}
The community service activity aims to optimize the potential of teachers in making presentations through collaboration. Meaningful collaboration media presentations that will be used are done together. This makes the presentation made better, more complete, and has an attractive appearance. SMK Catur Global is a school that is adaptive to the development of learning technology. One of them is the technology of making teaching media in the form of presentations. Prezi application is used to make presentations that allow collaboration between teachers to make presentation material. The implementation method begins with (1) Introduction: create virtual classes using google classroom. Then upload the application and material and register all training participants in the classroom. The application was installed before the training. Stage (2) Implementation: We explained the importance of innovation in making presentations and the importance of teamwork, participants were divided into small groups according to their fields, and demonstrated their use using computers. Each group chooses one teaching material to make their presentation. Each group made a presentation of the teaching material. Each group can discuss with the speaker if experiencing difficulties. Stage (3) Evaluation: each group presents their work and uploads it to the virtual class. The speaker gave input so that the presentations made could be better. The results of this training train teamwork in producing the best work, train creativity in using computer application technology to improve learning outcomes, make teaching effective, make it easier to see material in one main picture.
\end{abstract}

Keywords: Community Service, Prezy, Team Work, SMK Catur Global

\begin{abstract}
Abstrak
Kegiatan pengabdian kepada masyarakat ini bertujuan untuk mengoptimalkan potensi guru dalam membuat presentasi melalui kolaborasi. Kolaborasi bermakna media presentasi yang akan digunakan dikerjakan secara bersama-sama. Hal ini menjadikan hasil presentasi yang dibuat lebih baik, lengkap, dan memiliki tampilan yang menarik. SMK Catur Global merupakan sekolah yang adaptif terhadap perkembangan teknologi pembelajaran. Salah satunya adalah terhadap teknologi pembuatan media ajar berupa presentasi. Aplikasi Prezi digunakan untuk membuat presentasi yang memungkinkan terjadi kolaborasi antar guru dalam membuat materi presentasi. Metode pelaksanaan diawali dengan (1) Pendahuluan: membuat kelas maya menggunakan google classroom. Kemudian mengunggah aplikasi dan materi serta mendaftarkan semua peserta pelatihan pada classroom tersebut. Aplikasi sudah diinstal sebelum pelaksanaan pelatihan. Tahap (2) Pelaksanaan: Kami menjelaskan pentingnya inovasi dalam pembuatan presentasi dan pentingnya kerjasama tim, peserta dibagi dalam kelompok kecil sesuai bidangnya, dan mendemonstrasikan penggunaanya menggunakan komputer. Setiap kelompok memilih satu materi ajar untuk dibuatkan presentasinya. Setiap kelompok membuat presentasi dari materi ajar tersebut. Setiap kelompok dapat berdiskusi dengan pemateri jika mengalami kesulitan. Tahap (3) Evaluasi: setiap kelompok mempresentasikan
\end{abstract}


karyanya dan mengunggah pada kelas maya. Pemateri memberi masukan agar presentasi yang dibuat dapat lebih baik. Hasil pelatihan ini melatih kerja sama tim dalam menghasilkan karya terbaik, melatih kreatifitas dalam penggunakan teknologi aplikasi komputer untuk meningkatkan hasil belajar, mengefektifkan cara mengajar, memudahkan melihat materi dalam satu gambar utama.

Kata Kunci: Pengabdian Masyarakat, Prezi, Tim Kerja, SMK Catur Global.

\section{Pendahuluan}

Dosen memiliki kewajiban untuk melakukan tridharma perguruan tinggi yaitu pengajaran, penelitian, dan pengabdian masyarakat (UU Guru dan Dosen, 2005). Pengabdian kepada masyarakat merupakan program dosen untuk menerapkan ilmu pengetahuan untuk mensejahterakan dan mencerdaskan masyarakat (Mentri Riset, 2015). Kegiatan pengabdian kepada masyarakat wajib dilakukan dosen sebanyak satu kali dalam satu semester. Hal ini dilakukan agar ilmu dan pengetahun yang dosen miliki bukan hanya bermanfaat di ruang kelas perkuliahan tetapi juga dapat menyelesaikan permasalahan di lingkungan masyarakat.

Masyarakat yang menjadi sasaran kegiatan ini adalah Sekolah Menengah Kejuruan (SMK) Catur global. Secara geografis, SMK Catur Global berada dalam satu kelurahan dengan lokasi Universitas Bhayangkara Jaya (UBJ), yaitu di kelurahan Marga Mulya Kota Bekasi. SMK Catur Global memiliki 30 guru mata pelajaran yang tersebar dalam 3 kompetensi keahlian, yaitu Teknik Komputer Jaringan, Teknik Sepeda Motor, dan Rekayasa Perangkat lunak. Satu mata pelajaran yang diajarkan dapat terdiri dari 2 sampai 3 guru. Artinya para guru mempunyai tim dalam mengajar mata pelajaran yang sama. Ini merupakan tantangan sekaligus merupakan potensi dalam membangun suasana kerja yang saling bekerja sama dalam membuat media pembelajaran.

Media pembelajaran merupakan alat bantu agar informasi dapat diterima dengan baik oleh orang lain(Aotar, Adlim, \& Safrida, 2015). Media belajar sangat penting pengaruhnya terhadap proses belajar mengajar (Purnomo, Fathurrozi, Ismaniah, \& Lestari, 2019). Para guru selalu mencari cara efektif agar komunikasi dengan para siswa dapat dilakukan bervariasi dan menarik (Wirawan, 2015). Jika setiap guru membuat materi pelajaran yang sama masing masing maka akan tidak efisien. Disini diperlukan tim dalam membuat media pelajaran yang sama.

Untuk membuat media belajar secara digital dalam bentuk presentasi, umumnya para guru mengunakan aplikasi Ms PowerPoint (Perron \& Stearns, 2010). Kelemahan aplikasi ini adalah tidak dapat dikerjakan bersama - sama dalam satu waktu atau tidak dapat berkolaborasi. Kelemahan lainnya adalah materi yang disajikan urutannya linear. Sehingga terkesan monoton dalam penyampaiannya. Disinilah diperlukan alternatif dalam membuat materi digital presentasi menggunakan aplikasi Prezi. 


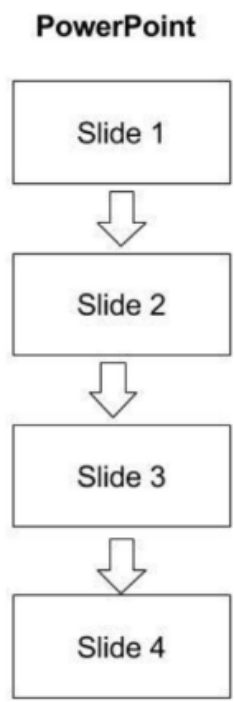

Linear Presentation
Prezi

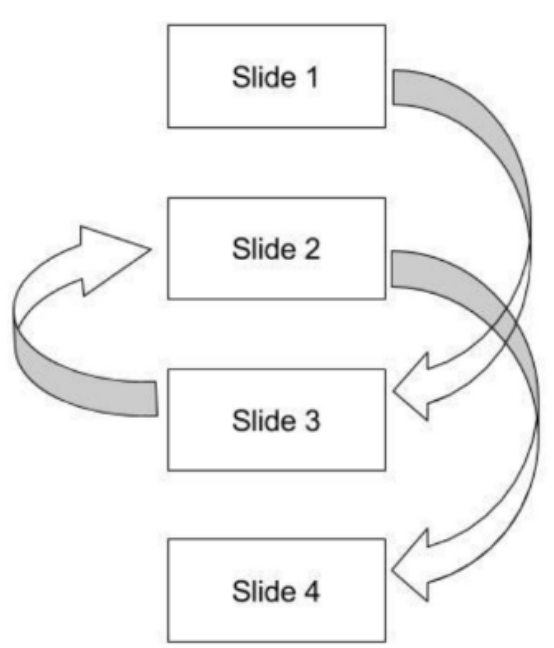

Non-linear Presentation

Gambar 1. Perbedaan Ms. PowerPoint dan Prezi (Chou, Chang, \& Lu, 2015)

Penelitian yang dilakukan oleh (Chou et al., 2015) yang membandingkan aplikasi Prezi dengan aplikasi presentasi tradisonal seperti Ms. PowerPoint dalam pengaruhnya terhadap hasil belajar siswa menunjukan aplikasi Prezi lebih efektif bagi siswa dalam mendapatkan pengetahuan. Gambar 1 menunjukan bahwa aplikasi presentasi tradisional mensyaratkan persiapan materi secara linear menggunakan pendekatan storyboard. Sebaliknya, aplikasi prezi dapat menggunakan keduanya, storyboard atau "mengalir bebas". Dengan aplikasi Prezi, presenter membuat presentasi di atas lembar kerja yang disebut Canvas, dimana semua elemen presentasi dapat terlihat. Kemudian, alur berjalannya presentasi diatur. Bermacam macam tools dapat digunakan untuk menghubungkan antar elemen agar pesan komunikasinya dapat sampai. Seperti aplikasi presentasi tradisional lainnya, aplikasi Prezi mampu untuk menampilkan teks, gambar, animasi, audio, dan video ke dalam satu materi presentasi. Kelebihan utama adalah aplikasi Prezi hadir untuk memberikan layanan digital presentasi yang memampukan kolaborasi antar presenter. Kolaborasi ini dilakukan dengan secara bersama sama mengerjakan proyek presentasi secara online (Prezi, n.d.)s.

Tujuan pengabdian kepada masyarakat ini adalah memberikan ilmu pengetahuan berkaitan dengan pentingnya bekerja secara tim dalam membuat proyek materi pelajaran dalam bentuk digital presentasi menggunakan aplikasi Prezi. Rutinitas pekerjaan yang dilakukan dapat lebih efisien dan efektif karena pekerjaan diselesaikan secara tim. Hasil pekerjaan berupa media pelajaran digital presentasi juga lebih baik dan menarik.

\section{Metode Pelaksanaan}

Kegiatan pengabdian kepada masyarakat ini dilakukan pada tanggal 16 Februari 2019 di SMK Catur Global Bekasi dengan tema "Kolaborasi Pembuatan Presentasi Menggunakan 
Aplikasi Prezi" selama 7 jam pelajaran. Strategi pelaksanaan dibagi menjadi tiga tahap, yaitu tahap pendahuluan, tahap pelaksanaan, dan tahapan evaluasi. Penjelasan metode pelaksaan pengabdian masyarakat dapat dilihat dari gambar 1 berikut:

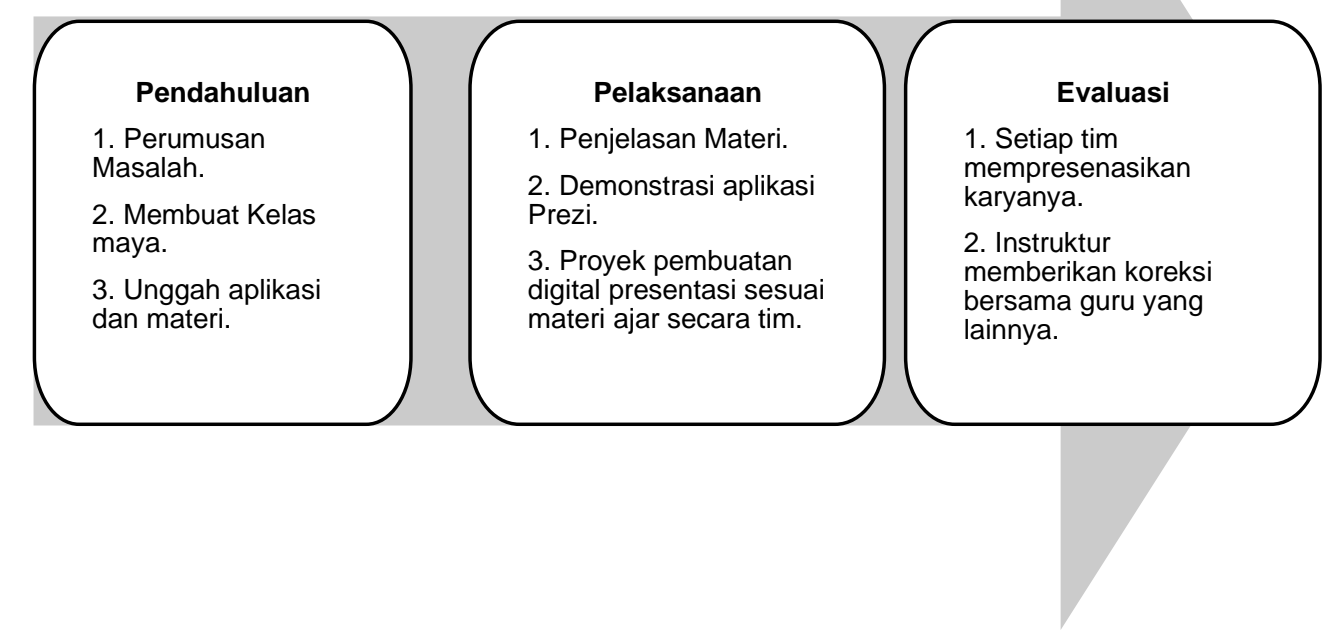

Sumber: Hasil Pelaksaaan (2020)

Gambar 1. Flow Pengabdian Kepada Masyarakat

Gambar 1 akan dijelaskan sebagai berikut :

\section{1) Tahap Pendahuluan}

Pada tahap ini, dilakukan analisis kebutuhan permasalahan proses pembelajaran di SMK Catur Global. Kami bertemu dengan wakil kepala sekolah bidang kurikum untuk melakukan wawancara dan diskusi tentang permasalahan dalam proses belajar mengajar. Berdasarkan hal tersebut, disimpulkan bahwa para guru memerlukan inovasi dalam pembuatan materi ajar dalam bentuk digital presentasi. Kami mengusulkan teknologi berupa aplikasi Prezi untuk membuat presentasi digital. Wakil kurikulum, yang mewakili para guru, saat kami wawancari pun menyetujui. Setalah itu, kami membuat kelas maya menggunakan goggle classroom. Master aplikasi Prezi dan materi pelatihan di unggah. Para guru diberikan kode untuk bergabung ke dalam google classroom. Para guru dibantu staf menginstal aplikasi Prezi sebelum pelatihan dimulai. Para guru akan dibuat kelompok berupa tim sesuai dengan mata pelajaran yang diajarkan.

\section{2) Tahap Pelaksanaan}

Pelaksanaan pelatihan dilaksanakan di ruang lab komputer Lt. 2 Gedung SMK Catur Global. Pelatihan dibuka dengan berdoa terlebih dahulu dengan harapan pelaksanaan pelatihan dapat berjalan dengan baik dan para guru dapat menerima ilmu secara maksimal. Kemudian Kepala Sekolah memberikan sambutan, dilanjutkan dengan sambutan perwakilan Universitas Bhayangkara Jakarta Raya. Kegiatan inti pun dimulai dengan dipresentasikan 
materi. Diawali dengan materi perrsiapan sebelum membuat presentasi, pentingnya bekerja bersama tim, dan dilanjutkan dengan demonstrasi dan totorial penggunaan aplikasi Prezi untuk membuat presentasi.

Indikator keberhasilan pelaksanaan pengabdian kepada masyarakat dalam bentuk pelatihan penggunaan aplikasi Prezi adalah adanya karya para guru dalam membuat materi digital presentasi sesuai dengan mata pelajaran yang diajarkan.

\section{3) Tahap Evaluasi}

Pada tahap evaluasi, para guru bersama timnya mempresentasikan karya di depan kelas. Mereka menjelaskan semua hal berkaitan dengan karyanya. Mulai dari filosofi pemilihan temlate, warna, tema desain, dan lain sebagainya. Mereka tidak mempresentasikan isi materinya, tetapi lebih ditekankan pada argumentasi penggunaan fitur - fitur yang ada dalam aplikasi Prezi. Instruktur bersama guru yang lainnya melakukan tanya jawab dan memberikan masukan untuk kesempurnaan karya mereka. Pada akhir sesi presentasi, secara terbuka kami musyawarahkan karya terpavorit. Dilihat dari kriteria kreativitas, komposisi warna, dan efisiensi penyusunan materi. Kemudian, semua karya di ungga dalam kelas maya.

\section{Hasil dan Pembahasan}

Kegiatan pengabdian kepada masyarakat ini diikuti oleh 30 guru SMK Catur Global. Setiap guru menggunakan komputer masing - masing di lab komputer. Gambar 2(a) merupakan foto kami bersama kepala sekolah dan staf kurikulum. Sedangkan gambar 2(b) menunjukan suasana pelatihan yang sedang berlangsung.

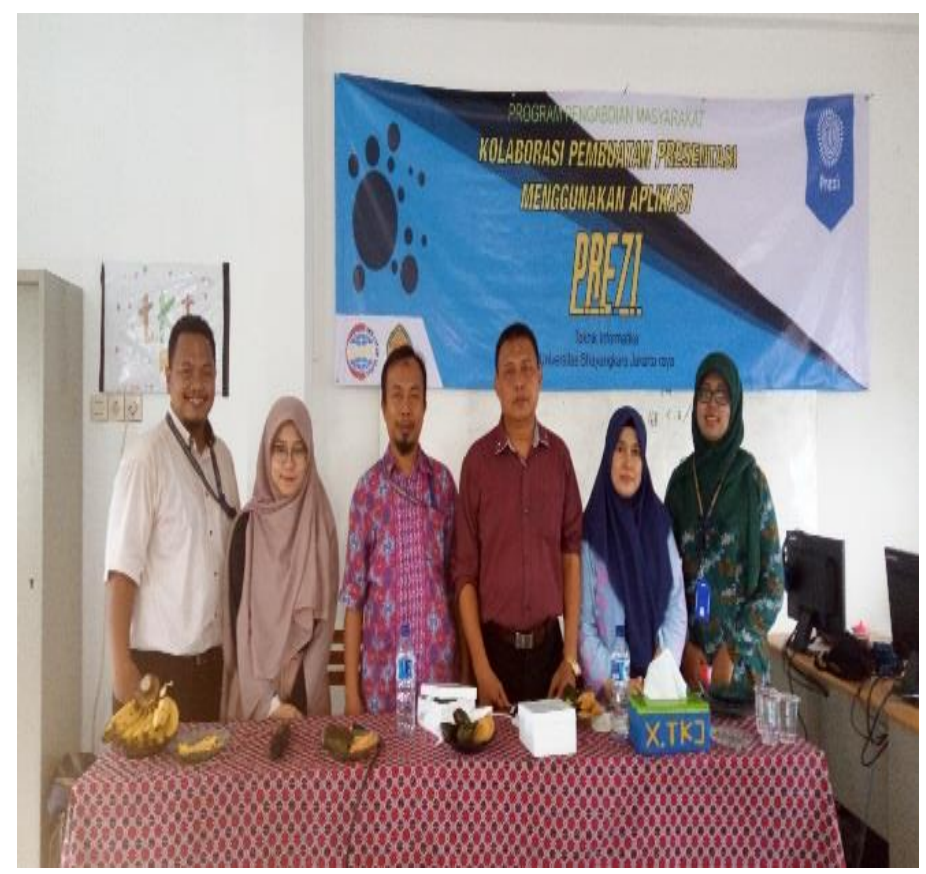

Sumber: Hasil Pelaksaaan (2020)

Gambar 2a. Foto bersama Kepala Sekolah dan Staf Kurikulum 


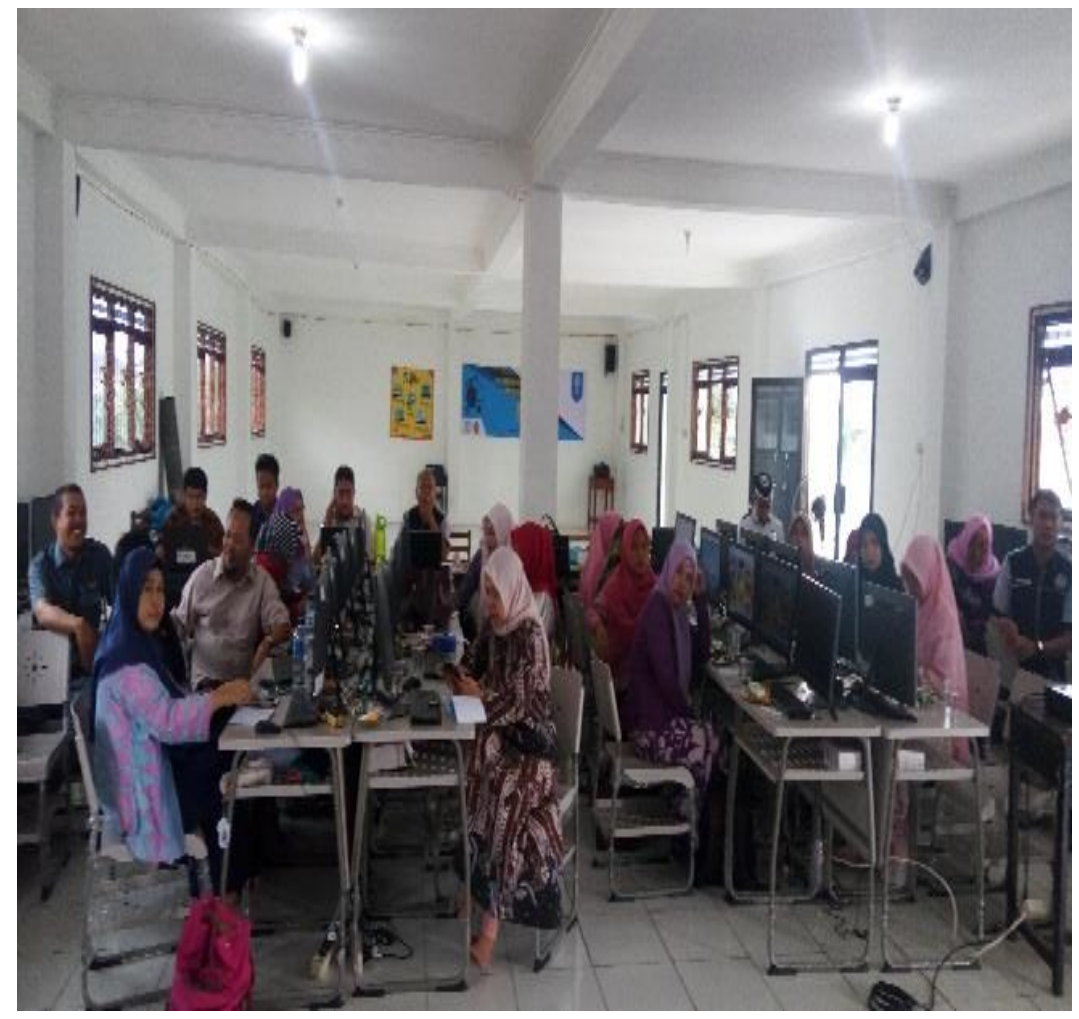

Sumber: Hasil Pelaksaaan (2020)

Gambar 2b. Para guru peserta Pelatihan

Gambar 3 merupakan hasil karya tim yang dipimpin oleh Ibu Sri. Tema yang diambil adalah materi Fungsi pada mata pelajaran Matematika. Canvas yang terlihat berupa cabang pohon yang terdapat ranting dan bunga. Ini merupakan "big-picture" dari tema fungsi yang dibuat. Lingkaran yang terlihat merupakan sub menu materi yang disajikan. Jika presentasiini dijalankan maka terjadi pergerakan dari satu mater ke materi lain secara dinamis.

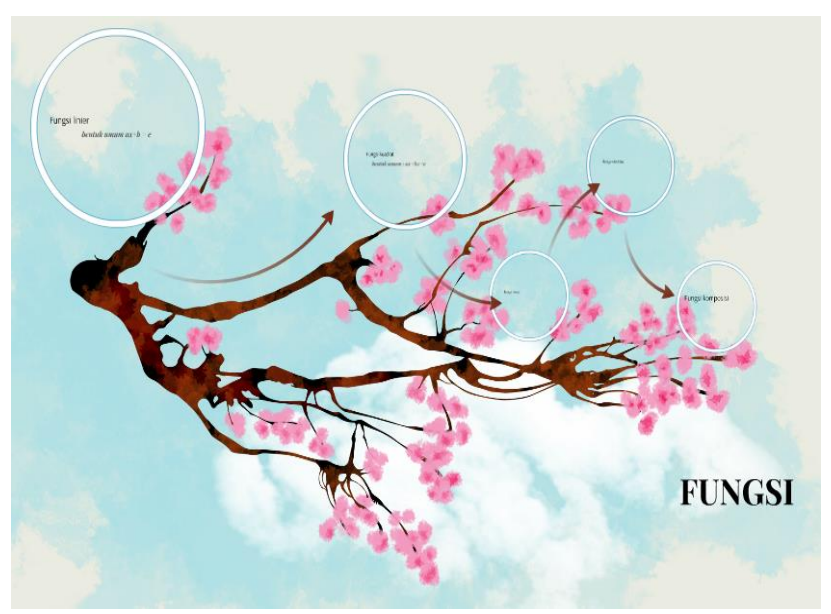

Sumber: Hasil Pelaksaaan (2020)

Gambar 3. Hasil Karya Ibu Sri 
Analisis kondisi SMK Catur Global :

\section{a) Sebelum dilakukan Pengabdian Kepada Masyarakat}

Para guru di SMK Catur Global belum mengetahui adanya aplikasi untuk membuat presentasi yang dapat dilakukan secara tim atau berkolaborasi, royek membuat presentasi dapat dilakukan secara bersama-sama. Walapun sebagian besar guru pernah menggunakan aplikasi Ms. PowerPoint untuk membuat presentasi.

\section{b) Sesudah dilakukan pengabdian Masyarakat}

Guru di SMK Catur Global setelah dilakukan pelatihan mengetahui dan mempraktekan langsung aplikasi Prezi yang menjadikan materi pelajaran disajikan lebih menarik. Alur materi tidak lagi diberikan secara linear tetapi juga non-linear

\section{c) Luaran Kegiatan Pengabdian Masyarakat}

Luaran Kegiatan ini terbuatnya materi digital presentasi pada mata pelajaran yang diajarkan oleh para guru. Materi ini nantinya akan disampaikan para guru kepada para siswanya di dalam kelas. Materi ini juga tersimpan dalam cloud storage yang dapat diakses bersama oleh setiap guru.

\section{Kesimpulan}

Berdasarkan hasil kegiatan pengabdian kepada masyarkaat yang telah dilakukan, dapat disimpulkan bahwa guru SMK Catur Global sangat tertarik dengan ilmu pengetahuan dan teknologi dalam bidang pengembangan media pembelajaran untuk meningkatkan kualitas pengajaran yang bermuara pada meningkatnya hasil belajar. Aplikasi Prezi digunakan untuk membuat materi digital presentasi yang memiliki tampilan lebih menarik, pengaturan warna yang dinamis, dan konsep "big-picture" dalam sebuah canvas dapat memudahkan daya terima siswa terhadap infromasi yang diberikan. Rekomendasi dari kegiatan ini adalah perlu diberikan penghargaan bagi para guru yang telah meningkatkan kualitas pengajarannya dengan membuat materi digital presentasi yang kemudian digunakan di dalam kelas selama proses belajar mengajar.

\section{Ucapan Terima Kasih}

Kami mengucapkan banyak terima kasih kepada semua pihak yang telah terlibat dalam kegiatan pengabdian kepada masyarakat ini baik langsung maupun tidak. Pertama, kepada Alloh Subhanalloohu Wata'ala dengan rahim-NYA kegiatan ini dapat terselenggara dengan baik serta lancar. Kedua, Kepala Sekolah SMK Catur Global beserta staf yang telah memberikan kesempatan kami untuk berbagi ilmu pengetahuan dan keterampilan. ketiga, kepada tim pengabdian kepada masyarakat atas kerjasama yang terjalin untuk kesuksesan kegiatan ini. Semoga Alloh Subhanalloohu Wata'ala memberikan keberkahan atas kegiatan ini dan memberikan pemahaman atas ilmu yang belum kami ketahui. Amiin. 


\section{Daftar Pustaka}

Aotar, Adlim, \& Safrida. (2015). Penerapan Presentasi Media Prezi pada Materi Sistem Saraf Manusia terhadap Keterampilan Berfikir Kritis Siswa Kelas XI SMA Negeri 2 Bukit. Jurnal EduBio Tropika, 3(2), 68-72.

Chou, P., Chang, C., \& Lu, P. (2015). Computers \& Education Prezi versus PowerPoint: The effects of varied digital presentation tools on students ' learning performance. Computers \& Education, 91, 73-82. http://doi.org/10.1016/j.compedu.2015.10.020

Indonesia, P. R. (2005). Undang Undang Tentang Guru dan Dosen (No. Nomor 14 Tahun 2005). Indonesia.

Mentri Riset, T. dan P. T. Standar Nasional Pendidikan Tinggi (2015). Indonesia.

Perron, B. E., \& Stearns, A. G. (2010). A Review of a Presentation Technology : Prezi, 000(00), 1-2. http://doi.org/10.1177/1049731510390700

Prezi. (n.d.). Prezi Presentation. Retrieved from http://www.prezi.com

Purnomo, R., Fathurrozi, A., Ismaniah, \& Lestari, T. S. (2019). Sukses Belajar Mengajar Menggunakan Mind Mapping dengan Aplikasi FreeMind. Abdimas UBJ, 2(1), 34-40.

Wirawan, A. W. (2015). Penerapan Media Pembelajaran Berbasis Prezi untuk Meningkatkan Hasil Belajar Administrasi Kepegawaian. In Seminar Nasional Pendidikan Ekonomi dan Bisnis. Surakarta: Universitas Sebelas Maret Surakarta. 